\title{
Review on African Animal Trypanosomosis and its Control Measures
}

\author{
Mohammed Shemsia* \\ Bahir Dar Animal Health Diagnostic and Investigation Laboratory, Bahir Dar, Ethiopia
}

*Corresponding Author: Mohammed Shemsia, Bahir Dar Animal Health Diagnostic and Investigation Laboratory, Bahir Dar, Ethiopia, Email: Mohammedshemsia@gmail.com

\begin{abstract}
Africa animal trypanosomosis is the main haemoparasitic disease in domestic animals and is caused by the protozoan parasite Trypanosoma. The parasite is transmitted biologically by the tsetse fly (Glossina species) and biting flies. T. vivax and T.congolense mainly infect livestock, and T.brucei infects both humans and animal. In Ethiopia, animal trypanosomosis is among the most important diseases limiting livestock productivity and agricultural development due to its high prevalence in the most arable and fertile land of South west and Northwest part of the country following the greater river basins of Abay, Omo, Ghibe and Baro, which has a high potential for agricultural development. African animal trypanosomosis is most important in cattle but can cause serious losses in pigs, camels, goats, and sheep. Trypanosomosis in livestock causes great losses in terms of mortality, abortion, reduced fertility, milk and meat production, and ability to work as traction animals. There are three main strategies for the controlling of Africa animal trypanosomosis. The first is to use drugs to combat the parasite itself, the second is to control vector of disease, tsetse fly which include using live targets (pour on), dour bait technology (traps and target) and biological vector control method. The third is exploitation of genetic resistance to trypanosomosis. The incidence of resistance to trypanocidal drugs is apparently increasing and the main means of controlling the disease is therefore under threat.
\end{abstract}

Keywords: Africa . Anaemia . Control . Glossina . Trypanosomosis

\section{INTRODUCTION}

Trypanosomosis is the main haemoparasitic disease in domestic animals and is caused by the protozoan parasite Trypanosoma. The parasite is transmitted biologically by the tsetse fly (Glossina species) and infects animals over an area known as the 'tsetse belt', which extends approximately 10 million $\mathrm{km}^{2}$ across 37 countries in Africa, from the Sahara Desert in the North to South Africa in the South [1]. In Ethiopia, tsetse born trypanosomosis is arguable the single most important disease, which excludes over $150,000-200,000 \mathrm{~km}^{2}$ fertile land in the west and south west of the country from agricultural production [2].

For several decades, Africa animal trypanosomosis has been considered a neglected tropical disease. African animal trypanosomosis has a very significant combined economic and health burden in Sub Sahara Africa [3,4]. The disease also has an additional impact on crop agriculture, human settlement and welfare, as approximately 7 million $\mathrm{km}^{2}$ of the region is rendered unsuitable for mixed crop-livestock farming systems [5]. AAT is estimated to cause annual losses of more than US\$ 4.5 billion dollars through direct and indirect agricultural production losses [6,5]. In Ethiopia, animal trypanosomosis is among of the most important diseases limiting livestock productivity and agricultural development due to its high prevalence in the most arable and fertile land of Southwest and Northwest part of the country following the greater river basins of Abay, Omo, Ghibe and Baro, which has a high potential for agricultural development [7].

Control methods of trypanosomosis in Africa are based on chemoprophylaxis, chemotherapy with trypanocide compounds and vector control interventions involve the use of insecticides either through sequential aerosol spraying technique (SAS); ground spraying; insecticidetreated targets or insecticide treated animals live baits; the use of traps, and the sterile insect technique [8].

In Ethiopia, several attempts have been made to control trypanosomosis in the country, with chemotherapy and chemoprophylaxis being the 
most widely applied methods. Vector-targeted control practices have been implemented mainly through specifically designed joint projects of the Ministry of Agriculture and other nongovernmental organizations [9].

A century ago, a huge number of tsetse elimination campaigns were implemented in Africa. The most successful large-scale method for the elimination of tsetse has been the use of insecticides applied either on the ground or from the air [10]. Hence the environmental impact of the spray of insecticide has led to the development of tsetse selective techniques like impregnated screens, traps and live baits [11]. However, targets, traps, livestock insecticide treatment and SAT are not fully effective to eradicate flies from an infested area, but they can reduce tsetse fly populations to levels that reduce the risks to animals, and can also be used as barriers to prevent reinvasion of flies into a previously cleared area [10]. The applications of these techniques are necessary prior to the implementation of the Sterile Insect Technique (SIT) because the tsetse population has to be drastically reduced before the release of irradiated sterile males [12].

A very limited trypanocidal compounds are available and they have been used for more than fifty years. The long-term use of the same molecules selected drug resistant strains of trypanosomes in many African countries [13]. The problems of drug resistance have been reported from 13 countries in sub-Saharan Africa including Ethiopia [14]. Therefore this paper reviews about trypanosomosis, the epidemiological information of trypanosomosis and the effective control and preventive strategies against the trypanosomosis.

\section{African ANimal Trypanosomsis}

African animal trypanosomosis (AAT) is a disease complex caused by tsetse-fly transmitted T. congolense, T. vivax, or T. brucei brucei, or simultaneous infection with one or more of these trypanosomes. In southern Africa the disease is widely known as Nagana, which is derived from a Zulu term meaning "powerless/useless" [15].

\subsection{Etiology}

African animal trypanosomosis is caused by protozoa in the family Trypanosomatidae genus Trypanosoma. Figure 1 illustrates the fundamental features of a trypanosome in a stained preparation made from the blood of an infected animal. T. congolense resides in the subgenus Nannomonas, a group of small trypanosomes with medium-sized marginal kinetoplasts, no free flagella, and poorly developed undulating membranes [16].

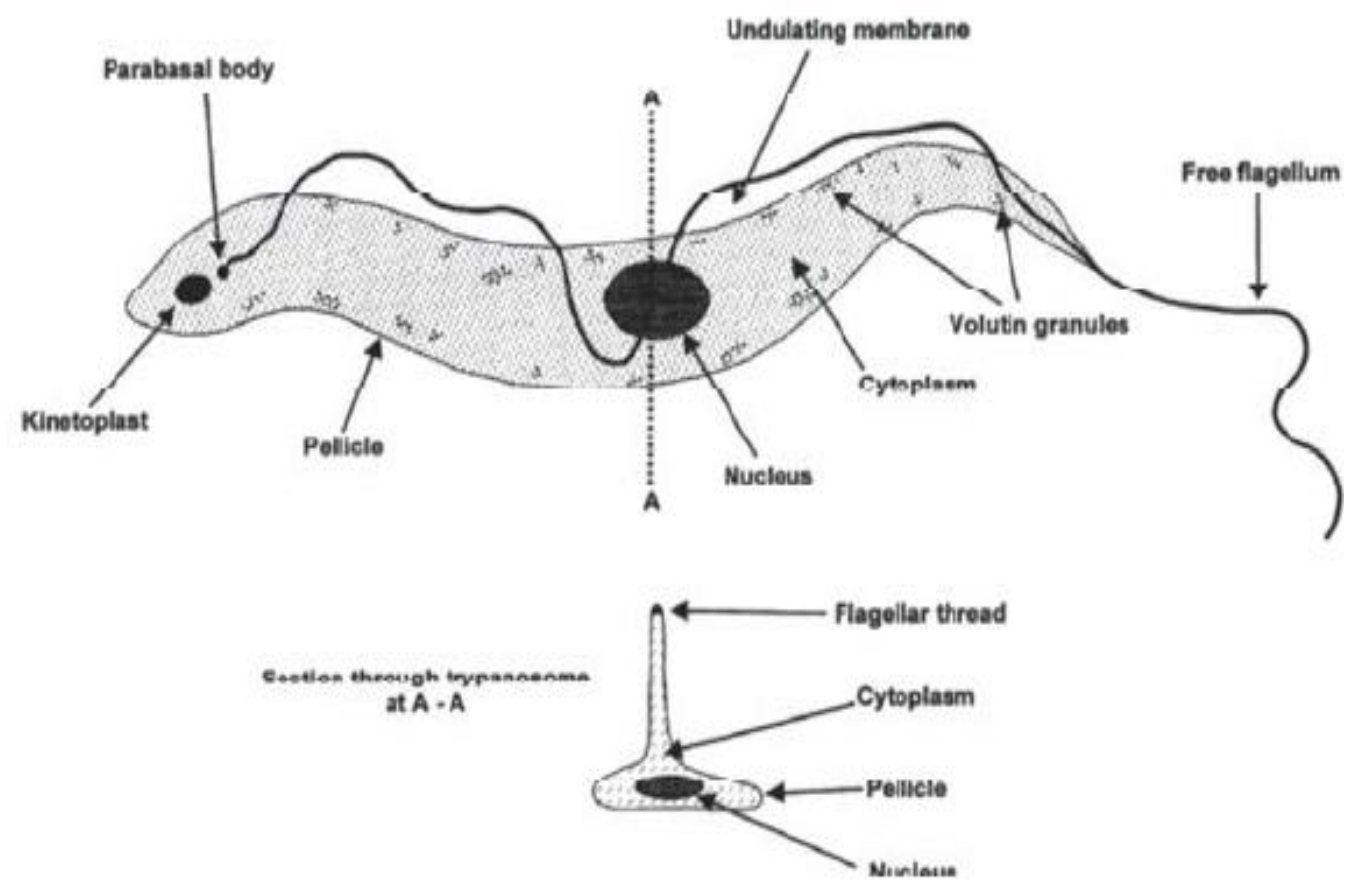

Fig1: Diagram of a trypanosome showing the fundamental morphological features

Source: (16)

T. vivax is a member of the subgenus Duttonella, a group of trypanosomes with large terminal kinetoplasts, distinct free flagella, and inconspicuous undulating membranes. T. vivax 
is a large (18-26 $\mu \mathrm{m}$ long) monomorphic organism that is very active in wet-mount blood smears.

T. brucei brucei resides in the subgenus Trypanozoon. T. b. brucei is an extremely polymorphic trypanosome occurring as short, stumpy organisms without flagella, long slender organisms with distinct flagella, and intermediate forms that are usually flagellated [17].

\subsection{Vector}

Tsetse flies (Glossina spp.) are found only in Africa. They are the biological and/or mechanical vector of trypanosomes and constitute a potent and constant threat to humans and livestock over much of sub-Saharan Africa. Thirty-one species and subspecies of these tsetse flies have been identified. Only a few species are vectors of human sleeping sickness but all are potential vector of animal trypanosomosis. Tsetse flies are robust, $6-15 \mathrm{~mm}$ in length, and can be distinguished from other biting flies by their forward-pointing mouthparts (proboscis) and characteristic wing. The historical classification of tsetse, based on morphological criteria, divides the species into three groups [18].

- The moristans group (savanna tsetse): this class occupies the savanna land of tsetse belt, and includes G.m.moristans,

- G.pallidipes, G.austeni,G.swynertoni.

- The palpalis group (riverine tsetse): this group invades river and lakeshores and encompasses G. fuscipes, G.palpalis,

- G.tachinoides and theirsubspecies.

- The fusca group (forest tsetse): this forest parts of tsetse belt, and includes G.fusca, G.brevipalpalis, G.longipennis, etc.

Tsetse feed exclusively on blood; they are holometaboulos insects with females giving birth to full-grown larvae which rapidly pupate in the soil. Their longevity, mobility and frequent feeding make these flies highly efficient vectors, but the low rate of population growth means even small increases in mortality rate can result in population decline and even extinction. Tsetse flies can fly at speeds of up to $25 \mathrm{~km}$ per hour, but they usually fly more slowly and only for short periods of time, e.g. up to 50 minutes and usually rest more than 23 hours per day in trees to avoid desiccation [19]. Trypanosomosis ( $T$. vivax) is also mechanically transmitted by other biting flies. The most important mechanical vectors are flies of the genus Tabanus, but Haematopota, Liperosia, Stomoxys, and Chrysops flies have also been implicated.

\subsection{Host Range}

Cattle, sheep, goats, pigs, horses, camels, dogs, cats, and monkeys are susceptible to AAT and may suffer syndromes ranging from subclinical mild or chronic infection to acute fatal disease. Rats, mice, guinea pigs, and rabbits are useful laboratory species. More than 30 species of wild animals can be infected with pathogenic trypanosomes, and many of these remain carriers of the organisms. Wild Equidae, lions, leopards, and wild pigs are all susceptible and can also serve as carriers of trypanosomes [21].

\subsection{Geographical Distribution}

African trypanosomosis can be found wherever the tsetse fly vector exists. $T$. vivax can spread beyond the "tsetse fly belt" by transmission through mechanical vectors. Tsetse transmitted African trypanosomosis is found between latitude $15^{\circ} \mathrm{N}$ and $29^{\circ} \mathrm{S}$ covering across over 37 countries in Africa from the southern edge of the Sahara desert to Zimbabwe, Angola and Mozambique [22]. It is the most economically important livestock disease of Africa, especially of cattle [23].

\subsection{Transmission}

In Africa, the primary vector for T. congolense, T. vivax, and T. $b$. brucei is the tsetse fly. These trypanosomes replicate in the tsetse fly and are transmitted through tsetse fly saliva when the fly feeds on an animal. T. vivax is also mechanically transmitted by other biting flies through the transfer of blood from one animal to another [20].

\subsection{Life Cycle}

The life cycle has two phases (Figure 2), one in the insect vector and the mammalian host. Most tsetse-transmission is cyclical and any pathogenic trypanosome may develop concurrent begins when blood from a trypanosome infected animal is ingested by the tsetse fly. The trypanosome loses its surface coat, multiplies in the fly, then reacquires a surface coat and becomes infective. T. brucei species migrate from the gut to the proventriculus to the pharynx and eventually to the salivary glands; the cycle for $T$. congolense stops at the hypopharynx and the salivary glands are not invaded; the entire cycle for $T$. vivax occurs in the proboscis [24]. 


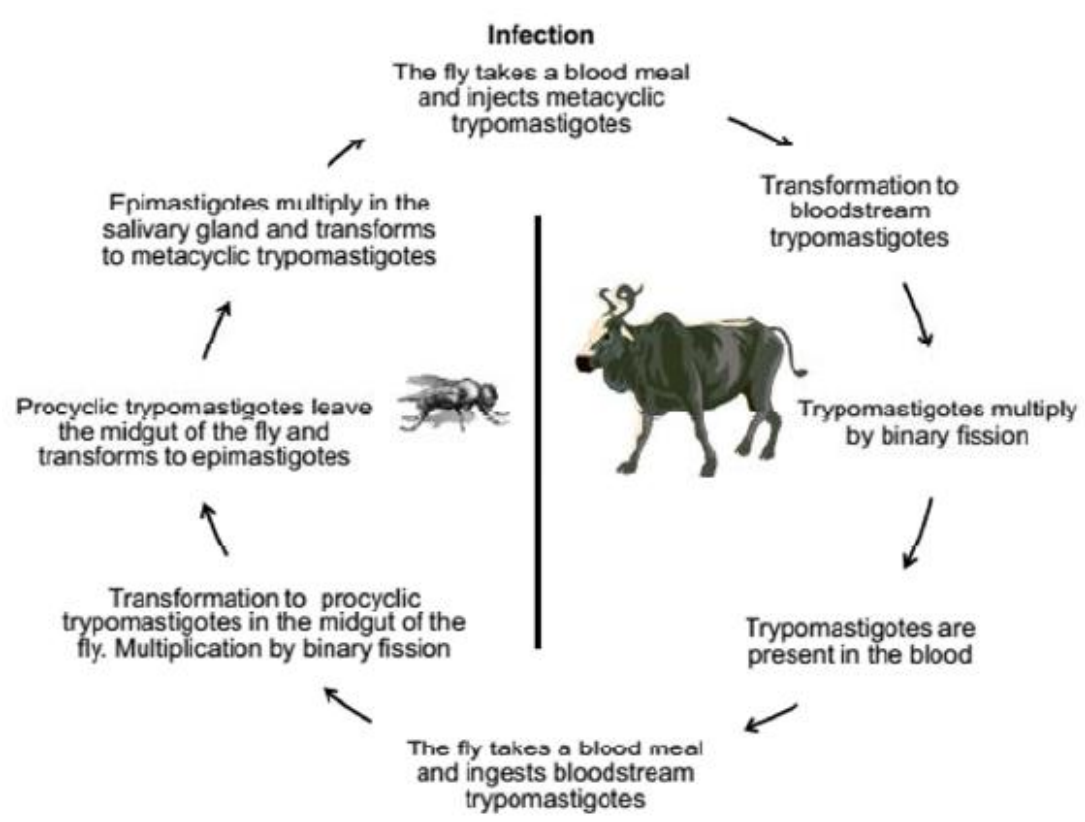

Fig2: The main phases in the life cycle of the trypanosome, both in the intermediate host (tsetse fly) and in the mammalian host.

Source: (24)

\subsection{Incubation Period}

The incubation period for $T$. congolense varies from 4 to 24 days; for T. vivax, from 4 to 40 days; and for $T$. b. brucei, from 5 to 10 days [25].

\subsection{Pathogenesis}

Pathogenesis of trypanosomosis in most species is a progressive, but not always fatal disease occurs and the main features are anemia, tissue damage and immunosuppression. Metacyclic trypanosomes are inoculated intradermally as the fly feeds. They multiply at this site provoking a local skin reaction (Chancre), which is most pronounced in a fully susceptible host and may be slight or absent with some strains or species of trypanosomes. Within the chancre, metacyclic parasites change to trypomastigote form, enter the blood stream directly or through the lymphatics and initiate characteristic intermittent parasitemias [26]. T. vivax usually multiplies rapidly in the blood of cattle and is evenly dispersed throughout the cardiovascular system, whereas $T$. congolense tends to be aggregated in small blood vessels and capillaries of the heart, brain and skeletal muscle. Both species exert their effect mainly by causing severe anemia and mild to moderate organ damage. The anemia has a complex pathogenesis involving mainly increased erythrophagocytosis, some hemolysis and dyshemopoiesis [27].
Very acute infection with $T$. vivax in cattle causes parasitemia and disseminated intravascular coagulation (DIC) with hemorrhages. T. brucei and rarely $T$. vivax have the added capability of escaping from capillaries into interstitial tissues and serous cavities where they continue to multiply. The cerebrospinal fluid is often invaded by $T$. brucei alone or mixed with other species or as a relapse after an apparently successful treatment. Animals chronically infected with any pathogen of trypanosome may develop concurrent and even fatal bacterial, viral and other protozoan infections as a result of immunosuppressant [28].

\subsection{Clinical Signs}

The cardinal sign observed in the African animal trypanosomosis is anaemia. Within a week of infection with trypanosome, there is usually pronounced decrease in PCV, haemoglobin, red blood cells and white blood cells levels and within two month these may drop to below 50 percent of their preinfecion value. T. vivax is considered to be less virulent for cattle than $T$. congolense, mortality rate of over $50 \%$ can occur [29]. Other primary clinical signs are an intermittent fever, lymphadenopathy and weight loss. Animals lose condition and become progressively emaciated. Milk yield may be decreased in dairy animals. Neurological signs, cardiac lesions, diarrhea, keratitis, lacrimation, appetite loss and other clinical signs have also been reported. Effects 
on reproduction include abortions, premature births and perinatal losses, as well as testicular damage in males. Deaths are common among chronically infected animals, and animals that recover clinically may relapse when stressed. Sudden deaths have been reported in small ruminants infected with $T$. vivax. Trypanosomes can cause immunosuppression and concurrent infections may complicate this disease [20].

\subsection{Gross and Post Mortem Lesions}

The gross lesions are nonspecific. In the acute stage, the lymph nodes and spleen are enlarged and petechiae are common on the serosal membranes, particularly in the peritoneal cavity. More chronic cases may have serous atrophy of fat and signs of anemia and the lymph nodes may be enlarged, normal or atrophied. Subcutaneous edema, excessive fluid in the body cavities, pulmonary edema and an enlarged liver may also be seen. Wasting or emaciation is common. Some trypanosomes can directly damage tissues, resulting in lesions such as keratitis or cardiac damage. Immune complexes also cause inflammation and damage in a variety of tissues, including the kidneys and blood vessels lesions [16].

\section{DiAgnosis}

The diagnosis of Trypanosoma infection is based on clinical signs and on the demonstration of the parasites by direct or indirect methods. The clinical signs of the AAT are indicative but are not sufficiently pathognomonic and diagnosis must be confirmed by laboratory methods.

Chemo-prophylactic drugs, administered at definitive intervals, and have a residual effect, as prevention depends on the persistence of the drug in the system of the animal. These drugs are used in conditions where the risk of the disease is so high that the health of the herds cannot be maintained by individual application of curative compounds. Other circumstance that might warrant the use of prophylactic drugs may occur when the infected animal cannot be reached (for instance, inaccessibility during rainy season, transhumance herds, trade cattle moving to long distance and passing through tsetse-belts etc.) [25].

The use of drug for the prevention and treatment of trypanosomosis has been important for many decades. In spite of this, some of the older chemoprophylactic drugs such as the quinapyramine derivatives Antrycide and Antrycide Prosalt are still used and give effective protection against $T . \quad b$. brucei infection in horses, camels, and cattle for up to 3 months. The most widely used of the newer chemoprophylactic drugs is isometamidium chloride. This drug, in use for over 20 years and sold under the trade names Samorin and Trypamidium, is excellent for the prophylaxis of all three African animal trypanosomes, and gives protection for 3-6 months. The development of resistance to this drug has been reported in both East and West Africa [13].

A very widely used chemotherapeutic drug is diminazine aceturate (Berenil), which is effective against all three African animal trypanosomes. The isometamidium drugs are also excellent chemotherapeutic agents as are the quaternary ammonium trypanocides Antrycide, Ethidium and Prothidium [35]. Some of the currently used trypanocide are listed (Table1) with their dosage rates and route of administration.

Chemo resistance may occur and care must be taken due to the presence of fake drugs on some markets [23]. The incidence of resistance to these drugs is apparently increasing and the main means of controlling the disease is therefore under threat [14]. Drug resistant trypanosomes develop through (i) under dosing, which may occur for a variety of reasons such as underestimation of animal body weight, over diluted solutions or incorrectly calculated dose volume (ii) incorrect injection or (iii) an incorrect strategy of drug use [36].

\subsection{Vector Control}

The fact that trypanosome are resistant to all commercially available drugs, including diminazine aceturate, homidium and isometamidium and that trypanotolerant livestock breed such as their have not been widely adopted in many areas of Africa because of their smaller size than the preferred zebu cattle, consequently changed the policy of the Programme Against African Trypanosomosis (PAAT) into encouraging control alternative against vector of the disease [37]. Vector control may play a role by reducing the level of tsetse challenge to the livestock which will intern encourage the development of land use practice involving livestock. Tsetse control remains the most theoretically desirable means of controlling the disease [21].

Before implementing vector-borne trypanosomosis control and /or eradication technique, it is essential that the exact extent and 
nature of the problem be fully assessed and established. Furthermore, the control measures should take into account such issues as efficiency of reducing vector population, feasibility, cost effectiveness, adverse effects on the environment and non- target organisms, community participation, etc. Several approaches to fly control have been used with varying degrees of success [21].

\section{Chemical control methods}

This method employs the use of synthetic pyrethroids such as deltamethrine, cypermethrin and permethrin and chlorinated hydrocarbon such as endosulphan, deledrin, which can be applied either to animal or on the environment in the form of ground spraying or aerial spraying [38].

\subsection{Ground spraying}

Ground spraying uses residual insecticides (e.g. dieldrin and endosulfan) which target the tsetse resting sites. Because of the negative effects on the environment these persistent insecticides are more and more replaced by the less toxic synthetic pyrethroids. Higher doses of residual chemicals are applied on resting sites of the target organism using motorized knapsack, which has proved very effective method particularly for riverinan and forest tsetse with linear dispersal [38].

\subsection{Sequential Aerial Spraying (SAS)}

Aerial spraying (SAS), which aims at spraying fine mist of no persistent chemical droplets that would kill flies by direct contact, uses helicopter and topography of the land [34]. It needs planes that fly at an approximate speed of 250-300 $\mathrm{km} / \mathrm{h}$ and the flight should be 10 to $15 \mathrm{~m}$ above the canopy. The SAS involves the ultra-low volume spraying of non-residual insecticides. Tsetse flies are killed by direct contact with the insecticide micro-droplets; there is no residual effect and treatments must be repeated until all newly emerging adults are affected. The SAS, in some cases in combination with other control tactics, was used successfully in several African countries, i.e. Botswana, where the Okavango delta was cleared from tsetse flies without negative impact on the environment [39]. In spite of this, aerial spraying has much limitation [37].

The classical direct parasitological methods for the diagnosis of trypanosomosis, namely microscopic examination of blood or lymph node, are not highly sensitive, but a number of techniques, including enrichment of the sample, rodent inoculation and molecular methods may increase the sensitivity [30].

Indirect methods rely on serological tests by detecting specific antibodies developed by the host against the infection or, inversely, to demonstrate the occurrence of circulating parasitic antigens in the blood by the use of characterized specific antibodies. The detection of antibodies indicates that there has been infection, but as antibodies persist for some time after all trypanosomes have disappeared from the organism (either by drug treatment or self cure) a positive result is no proof of active infection. On the other hand, circulating trypanosomal antigens are eliminated quickly after the disappearance of the trypanosomes and their presence therefore shows almost always that live trypanosomes are present in the animal [31].

Compared to standard parasitological techniques and serological methods, molecular diagnostic tools in particular the polymerase chain reaction; allow the detection of trypanosome infections with much lower parasite numbers, both in the vertebrate and in the insect host. The principles of molecular tests are the demonstration of the occurrence of sequences of nucleotides, which are specific for a trypanosome subgenus, species or even type or strain. A positive result indicates active infection with the trypanosome for which the sequences are specific, as parasite DNA will not persist for long in the host after all live parasites have been eliminated [32].

\subsection{Tsetse and Trypanosomosis Control Measures}

Control of AAT is the most challenging task. The number of tsetse and occurrence of trypanosomosis fluctuate greatly from many to barely detectable over periods of several years. Several control measures for trypanosomosis exist, and have existed for several years, but at a continental scale they are apparently less effective in relieving the disease constraint. Firstly, In many countries of Africa, the will to control trypanosomosis is present, but the total financial resources available do not permit this area to receive an allocation consistent with its position in the priority listing. With this it is also true at the international level, allocation in this area are also influenced by concerns about the possible changes in land-use that may result from improved trypanosome control, and their potential influence on land degradation and loss 
of biodiversity. In addition to this, there is lack of accurate estimation the cost of trypanosomosis and the economics of alternative control strategies employed under different livestock production systems [33].

There are three main strategies for the controlling of the disease. The first is to use drugs to combat the parasite itself, the second strategy is to control of vector of disease, tsetse fly. The third strategy is to use animals that are inherently tolerant to the effect of the use of the disease and are able to remain relatively productive even when infected [34]

\section{TRYPANOSOME CONTROL}

Include chemotherapy and chemoprophylaxis. These compounds disrupt or block one or more of vital processes, which are essential to the invading trypanosome. Certain drugs have specific effects on the enzyme systems or block metabolic processes/pathways, and this is true of most of the trypanociodal drug [25].

Chemotherapy, by stopping the multiplication of trypanosomes, helps the immune system to overcome the infection. Treatment will be more effective in well fed and rested animals, in which the immune system is not adversely affected by stress and lack of food. Curative mainly used where disease incidence is low and only a limited number of animals in a herd contract the disease during the course of a year [25].

- It requires a proper socio- economic survey and, hence, costly

- There is a rapid re-invasion of the area by tsetse

- Not all adults are killed and pupae remain unexposed

Generally, in chemical control operation both discrimination ground spraying and aerial spraying are not 'currently available, politically and environmentally acceptable'.

\subsection{Using Live Targets (Live Bait Techniques, Pour-On or Spot-On)}

These are highly effective against tsetse and have the additional advantage of controlling other flies and cattle ticks. This is the most recent technique which has been revived for tsetse/ trypanosomosis control and one which is now generating considerable interest. The introduction of synthetic pyrethroids in suitable residual formulations to apply to cattle as a dip or pour-on has made it feasible, in some situations, to combine the control of ticks and tsetse.

Successful trials have been carried out in which many thousands of cattle were dipped with deltamethrin. The technique is now being evaluated in several countries and promising results recorded. The use of live animals as a target to control tsetse flies offers a major possibility of reducing maintenance costs and combining tick control with tsetse control, may be accepted by many farmers as a mixed public private good [40].Pyrethroids can be applied as pour-on on the back or the flank of the animal. The product quickly diffuses into all parts of the body. Due to its easiness to use, cattle breeders use pour-on more and more as an alternative to spraying and dipping [41].

The application of insecticide on livestock has shown a great success in the control of tsetse flies. In Zimbabwe, it has a suppressive effect on G. pallides [42].In Burkina Faso, this technique was used successfully against G. $\mathrm{m}$. submorsitans and G. p. gambiensis in the zones of Satiri and Bekuy and the pastoral zone of Yalé. Similarly, the method was very successful in Tanzania [11].

The continuous use of insecticide-treated livestock led almost to the elimination of tsetse and trypanosomosis to an extent that prophylaxis measures against the disease was no longer needed [43]. In the Eastern Province of Zambia, the insecticide treated cattle method (cyfluthrin in pour on) resulted in a drastic decline in the incidence of trypanosomosis [44]. It has been suggested that the local application of insecticide in footbath could effectively contribute to tsetse fly control [45].

\subsection{Odour -Bait Technology (Traps and Targets)}

Another approach is the use of traps and insecticide impregnated targets. The deleterious effects of insecticides on the environment and non target organisms has so long led to the refinement of a new technology that is cost effective, safe, community participative, and easy to apply. This breakthrough was the invasion of odour- baited traps/targets, which have proved to be the most effective barrier to re- invasion and the most suppressive to tsetse population. The attractivity of traps and targets for tsetse flies depends on their shape, size, colour pattern, and this differs from species to species. They may attracted by black, white, red, and blue coloures, but landing response is the 
highest in black colour. For tsetse control, a simpler and cheaper device involves a suspended screen of blue and black cloth (often known as a tsetse target) impregnated with a biodegradable pyrethroid insecticide such as deltamethrin. Flies are attracted by the blue segments and land on the black segment, quickly succumbing to the insecticide. The effectiveness of traps and targets can be greatly enhanced by addition of appropriate odour bait. Such odour baits are acetone or octenol, bovine or buffalo urine $[46,47]$.

Trapping techniques have been greatly enhanced by development of designs that mimic the fly's perception of vertebrate hosts. These generally use blue and black cloth in a shape that attracts the flies and then funnels them upwards into a netting trap usually in the form of a monoconical (pyramidal) or biconical shape. The biconical trap is very effective for species of the palpalis group including G. palpalis and G. tachinoides. It is less effective for the morsitans and fusca groups although good numbers can still be caught of some species, e.g. G. pallidipes. The biconical trap is widely used throughout Africa for sampling many species of tsetse flies, although it has only been used for control of riverine species when it is usually treated with insecticide to enhance efficiency [46].

A large variety of traps and targets has been developed to attract and kill tsetse flies. Especially for the savannah tsetse species the efficacy of these traps/targets can be improved by using odour attractants. This technology is not sophisticated and environment friendly, it is labour intensive and too expensive for most African peasants [46].

The method of placement depends on local conditions and preferences. Traps can simply be put on a wooden or metal pole. In open windy areas the suspension of a trap from a branch or other support probably gives more wind resistance than putting it on a pole. Hanging traps in vegetation entails the risk that they will become entangled. Screens can be attached to two wooden laths or suspended from the branches of trees by ropes. However, screens are even more easily entangled in vegetation than traps and it is recommended that they be suspended from metal or wooden supports [48].

The best location for traps and screens depends on the type of habitat. In general, the best places have high densities of tsetse flies and are open and sunny. Such sites offer good visibility; flies that settle on the black screens are more likely to fly upward into the brightly lit upper cone of gauze where they are retained. Once the area has been selected, the trap can be moved to obtain maximum efficiency. To find out whether an impregnated trap is in a good place, count the total number of flies collected each day during the first week of operation. The results can be compared with those obtained with other traps, and unproductive traps can be moved to new sites [48].

Some drawbacks of traps and targets are:

- Community based fly suppression efforts are difficult to sustain. The motivation of the owners may diminish after the tsetse population has gone down.

- Traps and targets may be stolen for the cloth they contain.

- During the rainy season the rapidly growing vegetation may camouflage the trap or target, which thus loses its visual attractivity for the flies [48].

Preliminary observations indicate that certain types of traps and odour substances will also attract mechanical vectors of trypanosomosis, such as tabanid and stable flies. This may be of help in reducing mechanical transmission of the disease.

\subsection{Non Chemical Vector Control Measures}

The control of trypanosomosis by this method comprises biological approaches and alteration of environment in which the vectors survive.

\subsection{Biological Methods}

The concept of 'sterile male release' is based on the fact that tsetse females copulate only once, and if the male of a copulating pair is sterile the female will not produce offspring during her lifetime. Thus, a series of field trials were carried out to evaluate the impact of the release of Gamma-irradiated male tsetse on tsetse population in Nigeria and some African countries [49].

Although under field conditions it has been demonstrated that this approach can significantly reduce tsetse populations, the majority release is not a practical proposition because it is too sophisticated and too expensive [50]. In order to reduce the number of sterile males required it is necessary to carry out two to three insecticide sprays and then to release 12,000 sterile males per $\mathrm{km}^{2}$, even in areas where the tsetse density is low. As the effect is 
tsetse-species specific, the cost increases with the number of species to be controlled. Also, the breeding and maintenance of tsetse fly colonies requires microclimate that is cost intensive and also requires skills and technical staff [51].

Sterile insect technique (SIT) exploits the particular mating biology of tsetse, where by female flies rarely mate more than once. Male flies are therefore mass reared in the laboratory, sterilized by irradiation and released to mate with wild females. Females mated with sterile males are unable to produce offspring. Unlike all other tsetse control techniques, SIT has no effect on non-target organisms. Also unlike other techniques, SIT becomes more efficient at lower fly densities and is ideally suited to the final phase [8].

The Sterile Insect Technique (SIT) consists of the release of irradiated sterile male flies at a proportion of at least 10 sterile to one wild male so that they are able to compete with the wild male flies. When a sterile males mates with a

Table2: Sterile Insect Mass Rearing Facilities in Africa virgin female fly, this results in no offspring because female tsetse usually mate only once in their life. Following mating with sterile males the females become infertile for the remainder of their life spans. By continually releasing sterile males in quantities over a time span that is sufficient to cover several generations of target populations, the fertile population is progressively reduced [52].

SIT is often needed for the final eradication of tsetse flies. It is a very expensive technique because mass rearing of tsetse flies is necessary to provide huge amounts of sterile males which have to be released (preferably aerially) on a weekly basis for a period of 15 to 18 months. SIT is only effective when the population density of the target flies is very low which implies prior suppression of the flies using other techniques [53]. Mass rearing facilities currently in operation in support of SIT programs against tsetse in Africa is listed below in the table 2.

\begin{tabular}{|l|l|l|l|}
\hline \multicolumn{1}{|c|}{ Country } & \multicolumn{1}{|c|}{ Location } & \multicolumn{1}{c|}{ Species } & \multicolumn{1}{c|}{ Weekly capacity (millions) } \\
\hline Tanzania & Tanga & Glossina austeni & $60-100 \mathrm{a}$ \\
\hline Ethiopia & Kaliti & Glosssina pallidipes & 1,000 \\
\hline Burkina Faso & Bobo-Dioulasso & G.palpalis gambiensis & $40^{\wedge} 0 \mathrm{a}$ \\
\hline
\end{tabular}

aSterile male-only production, otherwise 50\% sterile males and 50\% sterile females. Source: [54]

An example of success of SIT was the eradication of Glossina austeni from the island of Unguja, Zanzibar [12]. Unfortunately, with the exception of Zanzibar, there are very few success stories of the use of SIT to eradicate tsetse flies. Although Unguja is a small island infested with only one tsetse species G. austeni. Contrarily to the theoretical 10:1 ratio of sterile males to wild males a ratio of more than 100:1 was needed on Unguja. This can be explained by the fact that contrary to the common belief some tsetse flies mate more than once [55]. This implies that huge tsetse breeding units have to be built in order to produce the required large amounts of sterile flies. The AW-IPM approach was introduced into the area of tsetse control on the Island of Unguja, Zanzibar, where a population of $G$. austeni Newstead was eradicated using the SIT combined with pour-on treatment of cattle and insecticide impregnated targets or screens [12].

The SIT was tested for the first time against $G$. $m$. morsitans in Tanzania [56] in the 1970's. The release of sterile males at a 12:1 ratio managed to maintain the population suppressed for 15 months at an $80-95 \%$ reduction level. The initial reduction was obtained by aerial spraying.
The release of sterile males was also successfully integrated with the deployment of insecticide impregnated targets to eradicate $G$. p. gambiensis Vanderplank, G. tachinoides Westwood and G. m. submorsitans Newstead from an agro pastoral zone of Sidéradougou in Burkina Faso $\left(3,000 \mathrm{~km}^{2}, 1983-1985\right)$ and $G$. p. palpalis (Robineau-Desvoidy, 1830) from a pastoral area in Nigeria $\left(1,500 \mathrm{~km}^{2}, 1982-\right.$ 1985) [57]. The SIT is non intrusive to the environment, has no adverse effects on nontarget organisms, is species specific and can easily be integrated with other biological control methods. However, the release of sterile insects is only effective when the target population density is low, it requires detailed knowledge on the biology and ecology of the target pest, and the insect should be amenable to mass rearing. In addition, the SIT necessitates efficient release and monitoring methods, which must be applied on an area-wide basis. However, to ensure the success of these control methods, factory-reared tsetse flies must be competitive with their wild counterparts and must exhibit a similar behavior in a natural environment [58]. The summary of SIT used in the control of tsetse flies in Africa is listed below in table 3 . 
The success of this area-wide campaign was a strong argument for the Pan African Tsetse and Trypanosomosis Eradication Campaign (PATTEC), to promote the use of SIT for the eradication of tsetse populations from selected areas in Africa after pre-release reduction of tsetse populations to $90-99 \%$ using other conventional techniques. Indeed, to be successful SIT needs to be applied directly after the conventional control which will reduce the tsetse population to a low density before performing the release of sterile males.

Table3: Use of SIT in the control of trypanosomosis in Africa

\begin{tabular}{|l|l|l|l|l|}
\hline Country & Tsetse Spp & Ratio IM/WM & Suppression (\%) & References \\
\hline Tanzania & G.m. morsitans & $12: 1$ & $80-95$ & Williamson et al., 1983 \\
\hline $\begin{array}{l}\text { Burkina } \\
\text { Faso }\end{array}$ & $\begin{array}{l}\text { G.p.gambiensis } \\
\text { G. } \text { tachinoides }\end{array}$ & $45: 1$ & 100 & Cuisance et al., 1984 \\
\hline Nigeria & G. p. palpalis & $10: 1$ & 100 & Takken et al., 1986 \\
\hline Zanzibar & G. austeni & $1: 1-10: 1$ & 100 & Vreysen et al., 2000 \\
\hline
\end{tabular}

* IM: irradiated males, WM: wild males

Source: [12]

\subsection{Alterations of the Environment}

Bush clearing, burning vegetation and destruction of wild games have been the commonly used approaches employed to alter the environment of the vector. Clearing of bushes and trees around settlement, landing places, fords on rivers and on either side of roads has been promising result, particularly in flies like G.palpalis which requires more shade.

Bush clearing as a method of tsetse control based on the fact that if there are not trees or bushes growing in an area, then it is nearly always impossible for tsetse to live there permanently as the action removes their resting site which provide cool shade and humidity. Removing feed of flies through wild games destruction, and breaking up their breeding sites by burning vegetation has been effective in the elimination of the morisitans group that preferably feed on big wild games. Nonetheless, the devastating effects of the above vector control methods on the environment (scaring of wild-games and the vanishment of plant biodiversity followed by deterioration of the environment) have made this approach universally banned [48].

\section{EXPLOITATION OF TRYPANOTOLERANT LIVESTOCK}

It is well known that genetically determined innate resistance to many diseases occurs in the animal populations which have been subject to natural selection by exposure to disease pressure over many generations. This is also true for trypanosomosis. This is based on the fact that certain breed of cattle (popularly the N'Dama breed, the Mutru and the Bauole' breed of West Africa) are able to survive in tsetse infested areas, whilst a degree of trypanotolerance has also been shown to occur in some Bos indicus zebu breeds for example, the Orma Boran. This trait, termed as Trypanotolerance is generally to the indigenous taurine breed of cattle in West and Central Africa. Trypanotolerance, the ability of some livestock breeds to survive, reproductive and remain productive under tsetse/tryps risk without aid of trypanocides, is practiced as a major option for sustainable livestock production in nineteen countries in the most humid parts of West and Central Africa [21].

The use of trypanotolerant cattle had it not been limited in availability (account only for $17 \%$ of the total cattle population of the continent), was a potential alternative strategy for coping with the problem. The most important trypanotolerant breed interms of this number is the N'Dama (Bostaurus), a descendant breed of humpless humatic of taurine origin. These cattle have existed in the region for over 5,000 years. Susceptibility studies have shown the N'Dama to be the most resistant breed followed by the smaller West African short-horned Zebu cattle, the large and more recently introduced Zebu is the most susceptible [59]. Trypanotolerance has been described as an economical and sustainable option for combating AAT [4].

Trypanotolerant livestock play a significant role in moderating the problem of tsetse/tryps in West and Central Africa, primarily through their use for food, traction and as a source of cash income in areas where livestock agriculture would otherwise not be possible. Trypanotolerant breeds are poorly utilized and accepted in husbandry practice because of their size, productivity and traction power compared with the larger zebu breeds [50]. Apart from cattle, breeds of sheep and goat living in the 
tsetse areas are also relatively trypanotolerant. This is particularly true of the Djallonk sheep and dwarf goats in West Africa [59, 60].

\section{CONCLUSION AND RECOMMENDATIONS}

Animal African Trypanosomosis is tsetsetransmitted trypanosomosis mainly caused by blood parasites of Trypanosoma. AAT is an economically devastating disease and a major constraint to livestock production in sub-saharan Africa. In Ethiopia, trypanosomosis is the main constraint in the livestock production leads serious economic impact on the country development. Common control methods of trypanosomosis in Africa are based on chemoprophylaxis, chemotherapy with trypanocide compounds and the elimination of vectors by various techniques, including the use impregnated screens, traps and live baits and the use of the sterile male insect technique. An alternative to the latter methods is the breeding of trypanotolerant livestock. Vector control is a long-term fight and therefore requires the involvement of decision makers, researchers and farmers. Until now, the use of trypanocidal drugs to treat or to prevent susceptible livestock against trypanosomosis remains the only control measure for most of the African farmers including Ethiopia. Moreover, recent situations of tsetse fly advances to previously unoccupied sites and development of trypanocidal drug resistance are thought to hamper the envisaged results of these efforts. Based on the above conclusion the following recommendations are forwarded.

- Strategic control of trypanosomosis focusing integrated approach (vector control and chemotherapy) should be strengthened to improve livestock production and agricultural development.

- Proper and strict follow-up of trypanocidal drugs treatment should be done by professionals and supervision of the field personnel by experts should be practiced.

- Further study should be conducted on the magnitude of the disease and sustainability of it is control measures.

- Attempt should be made to expand government and private veterinary services to serve the community.

\section{REFERENCES}

[1] Parryet, G.F., Mabey, R.D. and Gill, F., 2004. Principles of medicine in Africa. Cambrid University Press, London.

ARC Journal of Animal and Veterinary Sciences
[2] Abebe, G. and Jobre, Y., 1996. Trypanosomosis: A Threat to Cattle Production in Ethiopia. Revue. Med. Vet., 147: 897-902.

[3] Habil, N., Inuwa, M.H., Aimola, I.A., Udeh, M.U. and Haruna, E., 2012. Pathogenic mechanisms of Trypanosoma evansi infections. Res. Vet. Sci., 93: 13-17.

[4] Namangala, B., 2012. Contribution of innate immune responses towards resistance to African trypanosome infections. Scand. J. Immunol., 75: 5-15.

[5] Dagnachew, S., Bezie, M., Terefe, G., Abebe, G., Barry, J.D. and Goddeeris, B. M., 2015. Comparative clinico-haematological analysis in young Zebu cattle experimentally infected with Trypanosoma vivax isolates from tsetse infested and non-tsetse infested areas of Northwest Ethiopia. Acta Vet. Scand., 57: 24.

[6] Leigh, O., Emikpe, B. and Ogunsola, J., 2014. Histopathological changes in some reproductive and endocrine organs of Trypanosoma brucei infected West African Dwarf goat does Bulg. J. Vet. Med., 18: 31-39.

[7] Dagnachew, S., Aran K S., Getachew, A., 2005. The Epidemiology of tsetse transmitted Trypanosomosis in Abay (Blue Nile) basin of North West Ethiopia. Proceedings of the 28th meeting of the International Scientific Council for Trypanosomosis

[8] WHO, 2011. Vector control, Human African trypanosomiasis. Accessed time September 10, $2011 . \quad$ http:// www.who.int/mediacentre/factsheets/fs259/en/.

[9] MoA (Ministry of Agricultural), 1995. Ethiopian ruminant livestock development strategy.

[10] Grant, I.F., 2001. Insecticides for tsetse and trypanosomosis control: is the environmental risk acceptable? Trends Parasitol., 17: 10-14.

[11] Bauer, B., Amsler-Delafosse, S., Kabore, I., and Kamunga, M., 1999. Improvement of cattle productivity through rapid alleviation of African management practice in the Agropastoral zone of Yale, Burkina Faso. Animal trypanosomosis by integrated disease. Trop. Anim. Health Prod., 31: 89-102.

[12] Vreysen, M.J.B., Saleh, K.M., Ali, M.Y., Abdulla, A.M., Zhu, Z.R., Juma, K. G., Dyck, V.A., Msangi, A.R., Mkonyi, P.A., Feldmann, H.U., 2000. Glossina austeni (Diptera: Glossinidae) eradicated on the Island of Unguja, Zanzibar, using the sterile insect technique. Journal of Economic Entomology, 93: 123-135.

[13] Delespaux, V., Geysen, D., Van den Bossche, P., Geerts, S., 2008. Molecular tools for the rapid detection of drug resistance in animal trypanosomes. Trends Parasitol., 24: 236- 242. 
[14] Peregrine, A. S., 1994: Chemotherapy and delivery systems: Haemoparasites. Vet Parasitol., 54: 223- 248.

[15] Vreysen, M. J. B., 2001. Principles of areawide integrated tsetse fly control using the sterile insect technique. Med. Trop., 61: 397411.

[16] FAO, 2006. Corporate Document Repository. A field guide for the diagnosis, treatment and prevention of African animal trypanosomosis. Food and Agriculture Organization of the United Nations. 2006, http:// www.fao.org/DOCREP/.

[17] Moulton, J.E., Sollod, A.E., 1976. Clinical, serological and pathological changes in calves with experimentally induced Typanosoma brucei infection. Am. J. Vet. Res., 37:791.

[18] Bouyer, J., 2006. Ecologie des glossines du Mouhoun au Burkina Faso: intérêt pour l'épidémiologie et le contrôle des trypanosomoses africaines. Thèse de Doctorat d'Université Montpellier II.

[19] Hargrove, J.W., Torr, S.J., Kindness, H.M., 2003. Insecticid-treated cattle against tsetse (Diptera: Glossinidae): what governs success? Bull. Entomol. Res., 93: 203-217.

[20] Roder, P.L., Scott, J.M., Pegram, R.G., 1984. Acute Trypanosoma vivax infection of Ethiopian cattle in the apparent absence of tsetse. Trop. Anim. Hlth. Prod., 16: 141-147.

[21] Leak, S.G.A., 1999. Tsetse Biology and Ecology: Their Role in the Epidemiology and Control of Trypanosomosis. CAB International, Wallingford (UK).

[22] OIE, 2009. African Animal Trypanosomiasis Nagana,Tests Disease, Tsetse Fly disease. pp: 1-5.

[23] WOAH, 2012. Manual of Diagnostic Tests and Vaccines for Terrestrial Animals. Chapter 2.4.18. OIE, Paris. Last updated April http://www.cirdes.org/IMG/pdf/F_3_anglais.pd f].

[24] Stein, J., 2011. Trypanotolerance and Phenotypic Characteristics of Four Ethiopian Cattle Breeds. Doctoral Thesis, Swedish University of Agricultural Sciences, Faculty of Veterinary Medicine and Animal Science, Uppsala, Sweden.

[25] FAO, 1998. A field guide for the diagnosis, treatment and prevention of AAT. FAO, Rome.

[26] Jordon, A., 1996. Trypanosomosis Control and tsetse research Laboratory, Bristol., pp 13-19 Botswana'. Acta Tropica., 99, 2-3:184-199.

[27] Loses, G., Ikede, B., 2002. Review on pathology of diseases in domestic and laboratory Animals caused by Trypanosoma congolense, $T$. vivax, T.brucei, $T$. rhodesiense and T. gambiense. Vet. Path (suppl)., 9: 1-71.
[28] Luckins, A. and Gray. A., 2008. An extravascular site of development of Trypanosoma congolense. Nature (Lond), 272: 613-614.

[29] Murray, M. and Dexter, T.M., 1988. Anaemia in bovine African trypanosomiasis: A review. Acta Trop., 45: 389-432.

[30] Murray, M.P.K. and Mcintyre, W.I.M., 1977. An improved parasitological technique for the diagnosis of African trypanosomosis. Trans R Soc Trop Med Hyg., 71: 325-326.

[31] FAO, 2004. Production year book. FAO, Rome, Italy.

[32] Desquesnes, M., McLaughlin, G., Zoungrana, A., Davila, A.M., 2001. On the Detection and identification of Trypanosoma of African livestock through a single PCR based on internal transcribed spacer 1 of rDNA. Int $\mathbf{J}$ Parasitol., 31: 610-614.

[33] FAO, 1993. A field guide for the diagnosis, treatment and prevention of African Animal Trypanosomiasis. Rome, Italy. pp: 12-135.

[34] OAU(Organinization of African Union), 2001. Trypanosomosis, Tsetse and Africa. The year book report.

[35] Mare, C. j., 2004. African animal trypanosomosis, Veterinary science/ microbiology, University of Arizona, http:// www.vet.uga.edu/vpp/gray-book/Handheld /aat.htm

[36] Leak, S.G.A., 1998. Tsetse Biology and Ecology: Their Role in the Epidemiology and Control of Trypanosomosis. CABI Publishing, Wallingford. pp: 568

[37] Bourn, D., Reid, R., Rogers, D., Snow, W., Wint, W., 2001. Environmental change and the autonomous control of tsetse and trypanosomosis in sub-Saharan Africa. Environmental Research Group Oxford, Oxford, UK. pp: 248.

[38] Uilenberg, G., 1998. A field guide for the diagnosis, treatment and prevention of african animal trypanosomosis. Food and Agriculture Organisation of the United Nations. (FAO), Rome, Italy. pp: 87-98.

[39] Kgori, P. M., Modo, S., Torr, S. J., 2006. 'The use of aerial spraying to eliminate tsetse from the Okavango Delta of Botswana', Acta. Tropica., 99: 2-3,184-199.

[40] D'leteren, G., Authie, E., Wissocq, N., Murray, M., 1999. Exploitation of resistance to trypanosomes. CABI publishing, Wallingford, England. pp: 195-216.

[41] Leak, S.G., 1996. 'The contribution to the epidemiology and understanding tsetse transmitted trypanosomiasis', $\mathrm{PhD}$ thesis, Universiteit Utrecht.

[42] Thomson, J.W., Wilson, A., 1992. The control of tsetse flies and trypanosomiasis by the 
application of deltamethrin to cattle. Bull. Anim. Health Prod. Afr., 40: 5-8.

[43] Hargrove, J. W., 2000. A theoretical study of the invasion of cleared areas by tsetse flies (Diptera: Glossinidae). Bulletin of Entomological Research, 90: 201-209.

[44] Van den Bossche, P., De Deken, R., 2004. The application of bait technology to control tsetse. The Trypanosomiasis. Wallingford, CABI Publishing. pp: 525-532.

[45] Bouyer, J., Balenghien, T., Ravel, S., Vial, L., Sidibé, I., Thévenon, S., Solano, P., de Meeûs, T., 2009a. Population sizes and dispersal pattern of tsetse flies: rolling on the river? Mol. Ecol., 18: 2787-2797.

[46] Vale, GA., Torr, SJ., 2004. Development of bait technology to control tsetse. In The Trypanosomosiases. Wallingford, UK, CABI International. pp: 509-523.

[47] Rayaisse, J.B., Tirados, I., Kaba, D., Dewhirst, S. Y., Logan, J. G., Diarrassouba, A., Salou, E.,Omolo, M., Solano, P., Lehane, M.J., Pickett, J. A., Vale, G.A., Torr, S.J., Esterhuizen, J., 2010. Prospects for the development of odour baits to control the tsetse flies Glossina tachinoides and G. palpalis. PLoS. Negl Dis., 4: 3.

[48] Bouyer, J., Solano P., Cuisance D., Itard, J., Frézil, J.L., Authié, E., 2010. Trypanosomos Control methods, Paris. pp: 1936-1943.

[49] Allsopp. 2001. Options for vector control against trypanosomosis Africa (A Review). Trend Parasitol., 17(1).

[50] Chater, S., 2002. Tsetse control; The next 100 years. A report of the meeting organized by DFIDC (Department for International Development) animal health programme, Septemb.

[51] Seifert, H. S. H., 1996. Tropical Animal Health. Kluwe Academic Publishers, The Netherlands $2^{\text {nd }}$ ed. pp: 152-169.

[52] Feldman, U., 2004. The sterile insect technique as a component of area-wide integrated pest management of tsetse. Oxfordshire, CABI Publishing. pp: 565-582.
[53] Bett, B., 2003. An analysis of the impact of tsetse-repellents on the epidemiology of cattle trypanosomosis and its adaptation for the control of the disease in Kenya. A PhD proposal.

[54] Hendrickx, G., Napala, A., Slingenbergh, J. H. W., Palmer, H. B., 1995. Facteurs affectant le contrôle de la trypanosomose au Togo. In: International Scientific Council for Trypanosomiasis Research and Control (ISCTRC), Twenty Third Meeting, Banjul, The Gambia. Organisation of African Unity Scientific and Technical Research Commission (OUA-STRC): Nairobi, Kenya.

[55] Bonomi, A., Bassetti, F., Gabrieli, P., Beadell, J., Falchetto, M., 2011. Polyandry is a common event in wild populations of the tsetse fly Glossina fuscipes fuscipes and may impact population reduction measures. PLoS. Negl. Trop Dis., 5(6): 89-102.

[56] Williamson, D.L., Dame, D.A., Gates, D.B., Cobb, P.E., Bakuli, B., Warner, P.V., 1983. Integration of insect sterility and insecticides for control of Glossina morsitans morsitans (Diptera: Glossinidae) in Tanzania: V. The impact of sequential releases of sterilized tsetse flies. Bull. Entomol. Res., 73: 391-404.

[57] Cuisance, D., Politzar, H., Mérot, P., Tamboura, I., 1984. Les lâchers de mâlesirradiés dans la Campagne de lutteintégréecontre les glossines dans la zone pastorale de Sidéradougou (Burkina Faso). Rev. Elev. Méd. Vét. Pays trop., 37: 449-467.

[58] Vreysen, M. J. B., Saleh, K. M., Lancelot, R., Bouyer, J., 2011. Factory tsetse flies must behave like wild flies: a prerequisite for the sterile insect technique. Trop. Dis., 5(2).

[59] Murray, M., Morrison, W.I., Murry, P.K., Clifford, D.J., Trail, J.C.M., 1979. Trypanotolerance - A review. World Animal Review, 31: 2-12.

[60] ILCA, 1979. Trypanotolerant Livestock in West and Central Africa. ILCA monograph 2. ILCA Addis Ababa.

Citation: Mohammed Shemsia, Review on African Animal Trypanosomosis and its Control Measures. ARC Journal of Animal and Veterinary Sciences. 2019; 5(4):34-46. doi: dx.doi.org/10.20431/2455-2518.0504004.

Copyright: (C) 2019 Authors. This is an open-access article distributed under the terms of the Creative Commons Attribution License, which permits unrestricted use, distribution, and reproduction in any medium, provided the original author and source are credited. 